\title{
PERSPECTIVE
}

\section{p53: link to the past, bridge to the future}

\author{
Alea A. Mills ${ }^{1}$ \\ Cold Spring Harbor Laboratory, Cold Spring Harbor, New York 11724, USA
}

Although the p53 tumor suppressor was identified nearly three decades ago and plays a pivotal role in human cancer, its complexity continues to surprise the research community. Indeed, it was only recently discovered that p53 belongs to a multigene family that also includes p63 and p73 (Kaghad et al. 1997; Schmale and Bamberger 1997). Both $p 63$ and $p 73$ express an array of isoforms as a result of multiple promoter usage and alternative splicing (Yang et al. 1998; Zaika et al. 2002). This complexity within the $p 53$ gene family has, until now, been considered a unique feature of $p 63$ and $p 73$. In this issue, Bourdon et al. (2005) use currently available molecular techniques to revisit the structure of $p 53$, the founding member of this gene family. This work reveals that like the p53-related genes p63 and p73, p53 also makes use of several promoters and undergoes alternative splicing to generate multiple isoforms. Thus, a comparison of $p 53-$ related genes reveals strikingly similar traits among family members that produce a plethora of related but functionally diverse proteins that add further complexity to the role of p53-related proteins in development, cancer, and aging.

\section{Transcriptional initiation, the start of the story}

Sequence analysis reveals that p53-like genes in lower organisms such as the squid are more closely related to $p 63$ and $p 73$ than they are to $p 53$. Although invertebrates have a single $p 53$-like gene, mammals are equipped with three. These findings suggest that $p 53$ is the most recent member of this gene family that has apparently evolved in multicellular organisms to cope with the otherwise dire consequences of DNA damage (Kaghad et al. 1997; Schmale and Bamberger 1997; Yang et al. 1998). The structures of $p 63$ and $p 73$ and the notion that the $p 53$ gene family arose from triplication of a more ancestral gene such as $p 63$ (Yang et al. 1998) provided the impetus for taking another look at the structure of the $p 53$ gene. In this issue, David Lane's group (Bourdon et al. 2005) describes the characterization of p53 using current molecular biological techniques. Indeed, when p53 was first identified by Lane and Crawford (1979) and others as a protein interacting with the SV40 T-antigen, PCR had

${ }^{1}$ Correspondence.

E-MAIL mills@cshl.edu; FAX (516) 367-8874.

Article and publication are at http://www.genesdev.org/cgi/doi/10.1101/ gad.1362905. not yet been invented; this technology would not be reported for another seven years (Mullis et al. 1986; Mullis and Faloona 1987). Using a PCR-based approach, Bourdon et al. (2005) began by identifying transcriptional start sites within $p 53$. When primers specific for different exons that encode the p53 DNA-binding domain (DBD) were used to amplify capped p53 transcripts that are expressed in the normal human colon, five distinct products were generated (Fig. 1). Sequencing of the cDNAs that were generated when exon 4 reverse primers were used revealed that one of the products encoded the p53 isoform that was described previously (BienzTadmor et al. 1985; Lamb and Crawford 1986). However, two different transcripts were found that had different $\mathrm{N}$ termini and arose from distinct transcriptional start sites separated by 54 nucleotides within noncoding exon 1 . Although both of these transcripts encoded full-length p53, only the more 3' transcriptional start site had been described prior to this (Bienz-Tadmor et al. 1985; Lamb and Crawford 1986). The biological relevance of the newly discovered start site was not addressed, but it is interesting to speculate that different upstream activators of p53 might provide specificity by selectively modulating these different transcription initiation sites, thus assuring that diverse stimuli converge to activate p53 expression. It is possible that the different transcripts have distinct translation efficiencies and/or stabilities. Defining the precise transcriptional start sites and determining whether this tandem array of transcription initiation sites is conserved between species should help to determine whether the two different p53 transcripts have any biological significance.

When Bourdon et al. (2005) sequenced the cDNAs obtained with primers specific for exon 5 , three different products were generated (Fig. 1). These represented the two p53 transcripts initiated within exon 1 as described above, as well as a third cDNA that contained intron 4 sequence at its $5^{\prime}$ end, suggesting that this transcript was generated by a novel promoter located within intron 4 . By assaying different intron 4-specific primers for their ability to amplify p53 transcripts from total RNA pools obtained from different human tissues, the relative location of a previously unidentified transcriptional start site within intron 4 was identified. This newly identified transcript has a single open reading frame that encodes an N-terminally truncated p53 isoform containing an initiation codon at amino acid 133, which they named $\Delta$ 133p53 (Fig. 2A). Although transcripts encoding a p53 
Mills

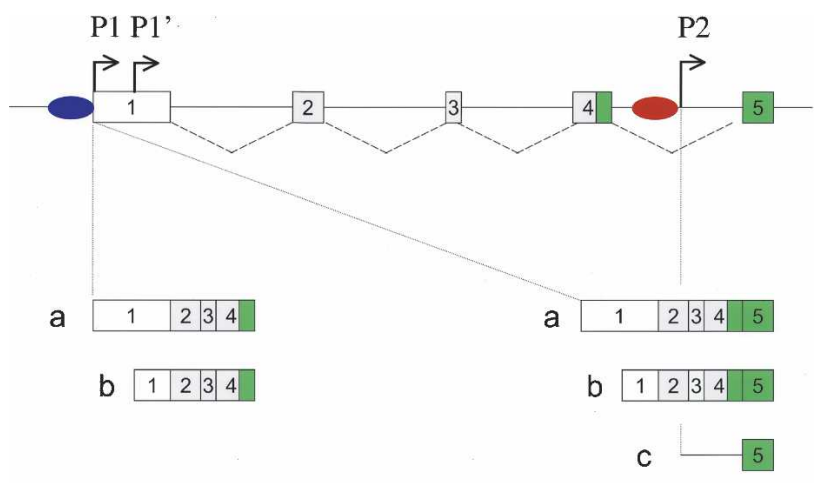

Exon 4 reverse primer

Figure 1. Identification of the $5^{\prime}$ end of p53 transcripts in normal human tissues. Schematic diagram of the $5^{\prime}$ end of the human p53 gene showing noncoding exons (white) and DBDencoding exons (green). (Left) A reverse primer specific for intron 4 amplified transcripts a and $\mathrm{b}$ from promoters $\mathrm{P} 1$ and $\mathrm{P} 1$, respectively (blue). A reverse primer specific for intron 5 amplified the transcripts a and b, as well as transcript c generated from promoter $\mathrm{P} 2$ within intron 4.

isoform with an N-terminal truncation of 40 amino acids (called p44 [Rovinski et al. 1987], $\Delta$ Np53 [Courtois et al. 2002], p53/p47 [Yin et al. 2002], and p47 [Ghosh et al. 2004], herein referred to as $\Delta 40$ p53 [Bourdon et al. 2005]) had been identified previously as a product of alternative splicing of intron 2 (Courtois et al. 2002; Ghosh et al. 2004) or altered translation initiation (Yin et al. 2002), the more extensive truncation in $\Delta 133 \mathrm{p} 53$ makes it distinct from $\Delta 40 \mathrm{p} 53$ (Fig. 2A). Indeed, $\Delta 40 \mathrm{p} 53$ retains the second transactivation domain, whereas $\Delta 133 \mathrm{p} 53$ is not only devoid of both $\mathrm{N}$-terminal transactivation domains, but is also missing the proline-rich domain implicated in growth suppression and apoptosis, as well as part of the DBD.

\section{p53 has dual promoters}

Identification of a novel p53 transcript that initiates within intron 4 prompted Bourdon et al. (2005) to assay this genomic region for promoter activity. When the putative intron 4 promoter was cloned upstream of a promoterless luciferase reporter and the intron 4-luciferase construct was introduced into p53-deficient cells, luciferase activity was induced approximately sixfold relative to the vector control, which the authors demonstrate is about as efficient as the polyomavirus promoter. The ability of this promoter to control initiation from the same transcriptional start site that they had identified within intron 4 was not shown. Nonetheless, this demonstrated that this region of intron 4 can indeed function as a promoter, at least in cultured cells. Although a second promoter in p53 had been described previously within intron 1 (Reisman et al. 1988), this promoter expresses a transcript that is unrelated to p53 (Reisman et al. 1996). Thus, Bourdon et al. have discovered that $p 53$

contains an internal promoter, making it much more similar to the dual promoter structure of $p 63$ and $p 73$.

\section{Alternative splicing defines the tail}

To identify p53 transcripts generated by this novel p53 promoter, intron 4-specific primers were used in combination with primers specific for the $3^{\prime}$ untranslated region within exon 11 to amplify cDNAs that contained both exons 5 and 11 . Using total RNA from several normal human tissues, three distinct p53 transcripts were generated (Fig. 3). The first transcript encoded full-length p53, while the other two p53-encoding transcripts had significant diversity due to an alternative exon located within intron 9. Thankfully, given the growing number of different isoforms that are being found for p53 family members, these transcripts were called $\beta$ and $\gamma$, to be consistent with the nomenclature devised for transcripts that produce p63 and p73. Instead of the normal pattern of splicing between exons 9 and 10 that occurs to generate full-length $\mathrm{p} 53$, the $\beta$ and $\gamma$ isoforms are devoid of amino acids encoded by exon 10, and instead are equipped with 10 and 15 novel amino acids, respectively, due to cryptic splice sites located within intron 9 that are promptly followed by premature stop codons (Fig. 3). Thus, the $\beta$ isoform terminates with the amino acids DQTSFQKENC, whereas the $\gamma$ isoform ends with MLLDLRWCYFLINSS. Because of this alteration, both $\beta$ and $\gamma$ isoforms encode proteins that contain the nuclear localization signal, but these isoforms lack the oligomerization domain that enables full-length p53 to form functional tetramers (Fig. 2A; Milner et al. 1991). Whether the unique peptides located at the $C$ terminus of the $\beta$ and $\gamma$ isoforms endow these proteins with novel function is currently unknown.

Transcripts similar to those encoding the $\beta$ isoform of p53 were first described in a human T-cell leukemia line (Chow et al. 1993), and have been characterized more recently in normal human cells and called p53i9 (Fig. 2B; Flaman et al. 1996). However, expression at the protein level had not been reported. In contrast to previous reports describing expression of $\mathrm{p} 53 \beta / \mathrm{p} 53 \mathrm{i} 9$ transcripts, the $\gamma$ isoform that Bourdon et al. (2005) identified had not been described previously. Although a second alternatively spliced p53 transcript called p53as (alternatively spliced) with a different $\mathrm{C}$ terminus had been described earlier (Wolf et al. 1985; Arai et al. 1986; Han and KuleszMartin 1992; Kulesz-Martin et al. 1994), these transcripts were generated by alternative splicing between exons 10 and 11 , and have been reported to be speciesspecific since this product was detected in mouse-but not in human-cells and tissues (Will et al. 1995; Laverdiere et al. 2000). Together with previous reports, this work has provided a fuller appreciation of p53 family diversity by revealing that nine different p53 proteins could potentially be expressed (Fig. 2A). Use of both the $\mathrm{P} 1 / \mathrm{P} 1$ ' and $\mathrm{P} 2$ promoters coupled with alternative splicing within intron 9 can generate p53, p53 $\beta$, p53 $\gamma$, $\Delta 133 \mathrm{p} 53, \Delta 133 \mathrm{p} 53 \beta$, and $\Delta 133 \mathrm{p} 53 \gamma$, as well as $\Delta 40 \mathrm{p} 53$, $\Delta 40 \mathrm{p} 53 \beta$, and $\Delta 40 \mathrm{p} 53 \gamma$ due to alternative splicing within 
A

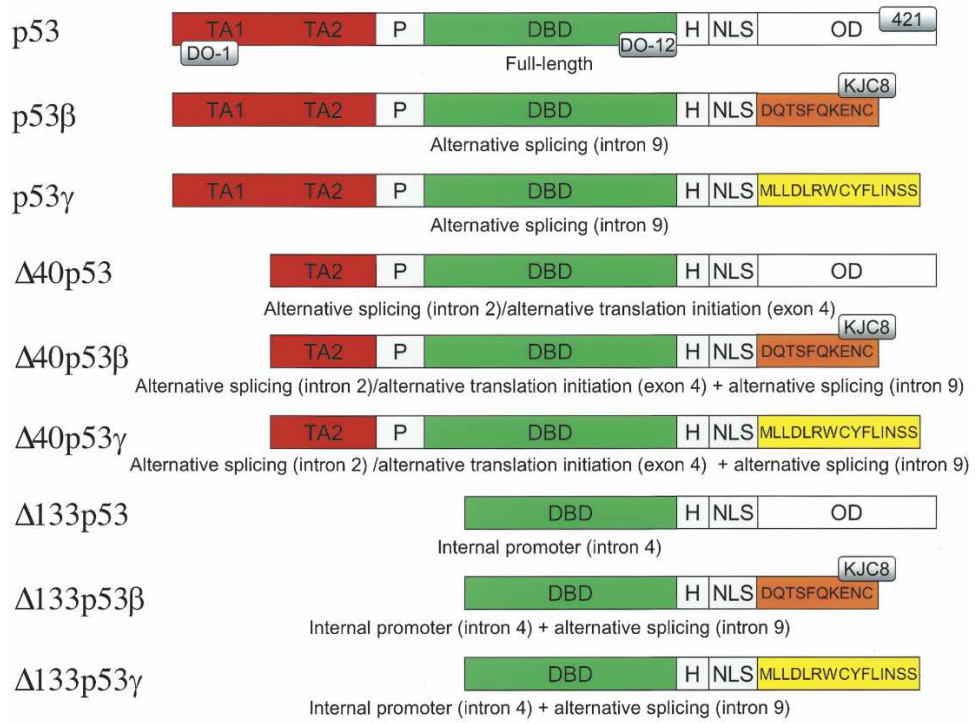

B

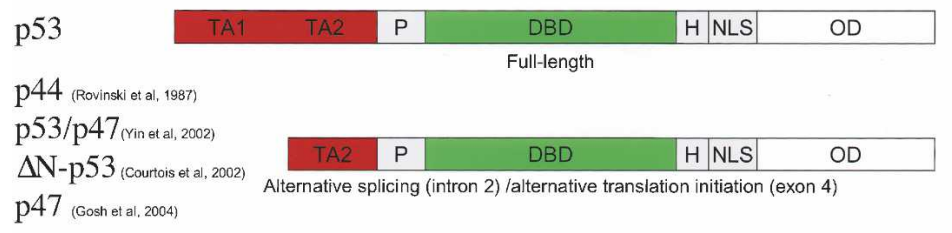

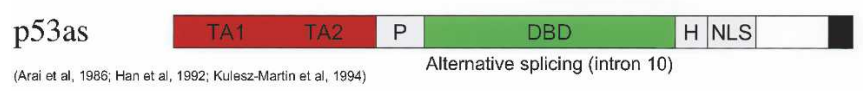

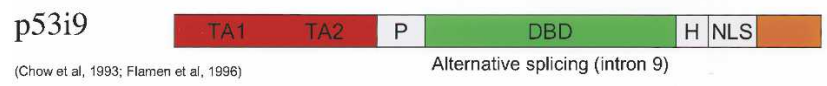

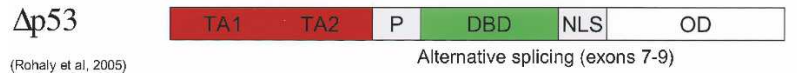

Figure 2. p53 isoforms. (A) p53 isoforms discovered by Bourdon et al. (2005). Full-length p53 showing transactivation domains 1 and 2 (TA1, TA2), proline-rich domain $(\mathrm{P})$, DNA-binding domain $(\mathrm{DBD})$, hinge region $(\mathrm{H})$, nuclear localization sequence (NLS), and oligomerization domain (OD), as well as the relative locations of the p53 monoclonal antibodies (DO-1, DO-12, 421) that were used to characterize p53 isoforms in this work. Other anti-p53 antibodies used in this study that are not shown include CM1 (raised against full-length p53) and sheep polyclonal (raised against the first 100 and the last 60 amino acids of the $\mathrm{N}$ and $\mathrm{C}$ termini, respectively). The three classes of isoforms have distinct $\mathrm{N}$ termini: full-length p53, $\Delta 40 \mathrm{p} 53$ (generated by alternative splicing/alternative translation initiation), and $\Delta 133$ p53 (generated by transcription from P2 shown in Fig. 1). Alternative splicing at the $C$ terminus generates full-length, $\beta$, and $\gamma$ isoforms for each of the $\mathrm{N}$-terminal classes. Unique $\mathrm{C}$-terminal residues of the $\beta$ and $\gamma$ isoforms are depicted. The KJC8 antibody was raised against the unique $C$ terminus of the $\beta$ isoforms. $(B, t o p)$ Schematic diagram of $\mathrm{p} 53$ showing transactivation domains 1 and 2 (TA1, TA2), proline-rich domain $(\mathrm{P})$, DNA-binding domain (DBD), hinge region $(\mathrm{H})$, nuclear localization sequence (NLS), and oligomerization domain (OD). Previously described p53 isoforms are generated by either alternative splicing or alternative translation initiation. The $\mathrm{N}$-terminally truncated isoform designated p44; p53/p47; $\Delta \mathrm{N}$-p53; p47 (referred to as $\Delta 40$ p53) lacks TA1 (Rovinski et al. 1987; Courtois et al. 2002; Yin et al. 2002; Ghosh et al. 2004). The C-terminally deleted isoform from mouse, p53as (alternatively spliced), is missing the last 30 amino acids of full-length p53 (Wolf et al. 1985; Arai et al. 1986; Han and KuleszMartin 1992; Kulesz-Martin et al. 1994), and the C-terminally truncated isoform from humans, $\mathrm{p} 53 \mathrm{i} 9$, is missing the last 60 amino acids of full-length p53 (Chow et al. 1993; Flaman et al. 1996). $\Delta \mathrm{p} 53$ has a deletion of 66 amino acids that encompasses part of the core DBD; this deletion maintains the reading frame (Rohaly et al. 2005). p53ß $(A)$ is identical to p53i9 (B) (Chow et al. 1993; Flaman et al. 1996). intron 2 (Courtois et al. 2002; Ghosh et al. 2004) or alternative initiation of translation (Yin et al. 2002). Given the possibility of combining mechanisms of diversity, one has to wonder just how large the p53 isoform family will grow in the future.

\section{p53 isoform expression at the protein level}

To investigate whether these various p53 transcripts can be translated into p53 proteins, p53-deficient cells were transiently transfected with expression constructs containing the different p53 cDNAs, and p53 isoform expression was assessed by Western analysis using p53specific antibodies. All p53 transcripts tested produced p53 proteins: A $45-\mathrm{kDa}$ protein was detected in cells transfected with p $53 \beta$, or p $53 \gamma$, as well as in cells transfected with $\Delta 40 \mathrm{p} 53$; a $35-\mathrm{kDa}$ protein was detected in cells transfected with $\Delta 133 \mathrm{p} 53$; a $28-\mathrm{kDa}$ protein was detected in cells transfected with $\Delta 133 \mathrm{p} 53 \beta$ and $\Delta 133 \mathrm{p} 53 \gamma$. This demonstrates that exogenously intro- duced cDNAs can be expressed in mammalian cells to generate p53 proteins.

To assess whether endogenous p53 isoforms were expressed in cultured cells, the DO-12 antibody (specific for the DBD) (see Fig. 2A) was used to detect p53 proteins in several transformed cell lines by Western analysis. The authors found that multiple bands ranging from 35 to $53 \mathrm{kDa}$ were detected in p53-expressing but not in p53-nonexpressing cells, supporting the notion that multiple p53 isoforms are expressed in cultured cells. It should be noted that the discovery of multiple p53 isoforms calls for a reevaluation of "p53-null" status in different cell lines. For example, p53 expression was evaluated here using the p53 antibody DO-12 raised against residues 256-270 of the core DBD (Fig. 2; Vojtesek et al. 1995). Therefore, although this antibody can detect the nine p53 isoforms described in this study, it does not detect $\Delta$ p53, a p53 isoform that was reported while this manuscript was in press, which has a deletion within the DBD (Fig. 2B; Rohaly et al. 2005). 
Mills

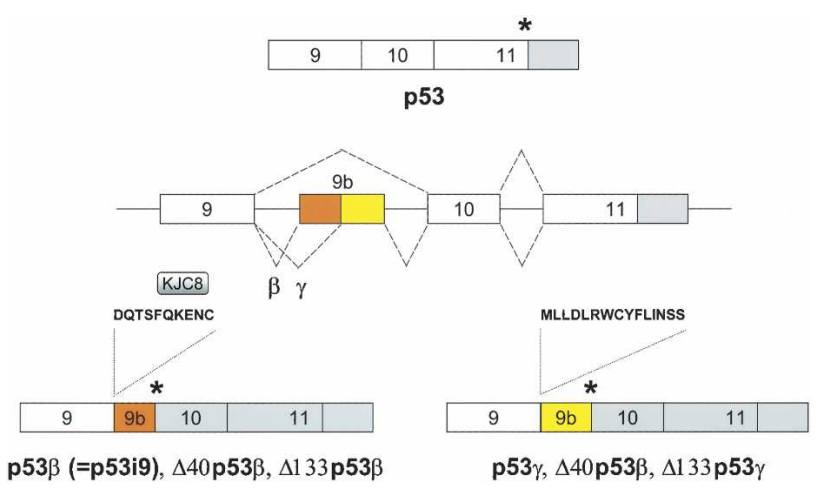

Figure 3. Alternative splicing at the $\mathrm{C}$ terminus. (Middle) $\mathrm{A}$ schematic diagram of the $3^{\prime}$ region of p53 is shown. Normal splicing between exons 9 and 10 generates full-length p53 (top), whereas a novel exon in intron 9 generates the unique $\beta$ (bottom left) or $\gamma$ (bottom right) sequence at the $\mathrm{C}$ terminus. Asterisks denote stop codons.

\section{Conservation from flies to humans}

To investigate whether the complex gene structure of p53 was evolutionarily conserved, the authors analyzed the structure of $p 53$ from Drosophila (dp53). By amplifying capped transcripts as they had done for human $p 53$, they identified two novel exons (A and B) positioned upstream of the previously identified $d p 53$ gene (Brodsky et al. 2000; Jin et al. 2000; Ollmann et al. 2000). This revealed that the promoter that had been characterized in earlier studies was in reality an internal promoter, an arrangement analogous to the dual promoter structure of human p53 (Bourdon et al. 2005), as well as for p63 and $p 73$. In addition, transcripts resulting from alternative splicing between exon B and exon 1 (similar to intron 2 alternative splicing that occurs to generate human $\Delta 40$ p53 [Courtois et al. 2002; Ghosh et al. 2004]) were detected. Thus, $d p 53$ expresses three distinct transcripts: the previously characterized dp53 transcript that encodes a 385-amino-acid protein, a novel transcript containing both exons $\mathrm{A}$ and $\mathrm{B}$ positioned $5^{\prime}$ of the dp53 transcript $(\mathrm{dp} 53 \mathrm{~L})$ that encodes a 495 -amino-acid protein, and a transcript containing only exons $\mathrm{A}$ and $\mathrm{B}$ (dp53n) that encodes a 110-amino-acid protein with only the transactivation domain. Bourdon et al. (2005) demonstrate that the dp53L transcript encodes a p53 isoform by showing that a p53-specific antibody can recognize the in vitro translated protein. A similar analysis was not possible for the novel dp53n transcript that contains only exons A and B since the encoded peptide would lack epitopes recognized by currently available p53 antibodies. Sequence alignment identified a five-residue sequence in the newly identified transactivation domain of dp53L that is evolutionarily conserved in multiple species; indeed, this sequence is present not only in p53, but in p63 and p73, suggesting that it performs a functional role in modulating the transcriptional ability of p53 family members. This analysis also supports the idea that dp53L is the fly equivalent of full-length p53, TAp63, and TAp73. Whether or not endogenous dp53L protein can also be detected in Drosophila tissue was not reported. Future studies will be required to determine whether p53 isoforms similar to dp53n that contain only the extreme $\mathrm{N}$ terminus are also expressed in mammals.

\section{Which p53 isoforms are expressed in vivo?}

To determine whether these distinct p53 transcripts are being expressed in vivo, an RT-PCR assay that could discriminate between full-length, $\beta$, and $\gamma$ isoforms of both the p53 and the $\Delta 133$ p53 classes was developed and used to screen a panel of normal human tissues. While p53 transcript was detected in all tissues analyzed, $\Delta 133$ p53 was detectable in most, but not all, tissues. $\beta$ and $\gamma$ isoforms for both the p53 and $\Delta 133$ p53 isoforms were expressed in a complex pattern. Colon and bone marrow were the only tissues tested that clearly expressed all six of the p53 isoforms that were assayed. It was fortuitous that colon was one of the tissues that Bourdon et al. (2005) originally selected for identifying p53 transcripts encoding different isoforms; whether other tissues had to be screened prior to this "positive" result was not mentioned. Lung and kidney tissues had the same pattern of isoform expression for both the p53 and $\Delta 133$ p53 classes (lung expressed p53 and $\Delta 133$ p53 only, whereas kidney expressed p53/p53 $\gamma$ and $\Delta 133 \mathrm{p} 53 /$ $\Delta 133 \mathrm{p} 53 \gamma$ ), demonstrating that both the $\mathrm{P} 1 / \mathrm{P} 1$ ' and the P2 promoters were active, and that the pattern of Cterminal splicing was consistent between p53 and $\Delta 133$ p53 transcripts in these tissues. Breast tissue was unique in that it expressed all classes of p53 transcripts analyzed but did not express detectable levels of the corresponding $\Delta 133 \mathrm{p} 53$ transcripts. The take-home message from this analysis is that the pattern of p53 isoform expression is complex and appears to be tissue-specific, making it much more similar to the expression patterns of $p 63$ and $p 73$ than was realized previously. Since p53 protein levels do not necessarily correlate with p53 expression at the transcript level (Matlashewski et al. 1986; Miki et al. 1994), it will be necessary to determine if this is also the case for different p53 isoforms. Indeed, further investigation will be required to determine the physiological role(s) of individual p53 isoforms in normal tissues, as well as to investigate whether the tissue-specific pattern of expression is conserved in other species. Evidence to date suggests that there may be important differences between the p53 isoforms expressed in mouse and human cells; p53as appears to be rodent-specific (Will et al. 1995; Laverdiere et al. 2000), whereas the sequences that generate alternative splicing of $\Delta$ p53 are present in primates but not in mouse (Rohaly et al. 2005).

\section{p53 isoforms and cancer}

Although p53 status is often an indicator of a patient's response to anti-cancer therapies, a clear-cut correlation between p53 function and treatment response does not hold for breast cancer. To investigate whether expression 
of various p53 isoforms might be responsible for this clinical observation, breast tumors were analyzed for expression of different p53 isoforms. Thirty randomly selected breast tumors were analyzed for expression of $\mathrm{p} 53$, p53 $\beta$, p53 $\gamma, \Delta 133$ p53, $\Delta 133$ p53 $\beta$, and $\Delta 133$ p53 $\gamma$ using RT-PCR. Whereas normal human breast expresses only p53, p53 $\beta$, and p53 $\gamma$, but not any of the corresponding $\Delta 133$ p53 isoforms (see above), transcripts encoding $\Delta 133$ p53 isoforms are detected in the majority of breast tumors. Although all of these tumors express p53 transcripts, albeit at apparently different levels, p53 $\beta$ transcripts were detected in only one-third (10/30) of the breast tumors, whereas $\mathrm{p} 53 \gamma, \Delta 133 \mathrm{p} 53 \beta$, and $\Delta 133 \mathrm{p} 53 \gamma$ were not detected in any of the tumors analyzed. Thus, it appears that many of the breast tumors tended to lose expression of $\mathrm{p} 53 \beta$, while simultaneously gaining expression of $\Delta 133 \mathrm{p} 53$. The observation that an $\mathrm{N}$-terminally truncated isoform of p53 is up-regulated in tumors is strikingly reminiscent of the increasing number of reports demonstrating that enhanced p63 expression is a frequent theme in the vast majority of human cancers (Crook et al. 2000; Hibi et al. 2000; Yamaguchi et al. 2000; Ito et al. 2001; Quade et al. 2001; Wang et al. 2001, 2002; Choi et al. 2002; Di Como et al. 2002; Hu et al. 2002; Patturajan et al. 2002; Reis-Filho et al. 2002, 2003; Massion et al. 2003; Pruneri et al. 2005; Tonon et al. 2005). It will be interesting to determine whether tumors derived from tissues that normally express the N-terminally deleted p53 isoforms, such as lung or colon, retain expression of these isoforms during the tumorigenic process. In addition, it will be important to determine whether tumors with p53 missense mutations have a particular pattern of p53 isoform expression. Since only five of the tumors analyzed had mutant $\mathrm{p} 53$ while the majority had an abnormal pattern of p53 isoform compared to that of normal breast tissue, the authors speculate that an imbalance in isoform expression may thwart p53's tumor suppressive capabilities, thereby accelerating the tumorigenic process in the absence of $p 53$ mutation. Whether certain p53 isoforms can facilitate interactions with p53 proteins containing tumor-derived missense mutations, as has been shown for both p63 and p73 (Strano et al. 2000, 2002; Gaiddon et al. 2001) awaits further investigation.

\section{Generation of antibodies specific for different p53 isoforms}

An important step in elucidating the function of different p53 isoforms is the generation of antibodies that have the ability to discriminate among very similar proteins with distinct epitopes. Indeed, David Lane's group (Bourdon et al. 2005) has played a historical part in generating and characterizing p53 antibodies, making these reagents available to the p53 community. In keeping with this tradition, Bourdon et al. (2005) first characterized p53-specific antibodies that were already available to determine which isoforms they recognize. Three different p53-specific antibodies were tested (Fig. 2A): sheep polyclonal serum specific for epitopes within the first 100 amino acids and the last 60 amino acids of p53
(Midgley et al. 1992); DO-1, a mouse monoclonal antibody raised against an epitope located between amino acids 21-25 (Stephen et al. 1995); and DO-12, a mouse monoclonal antibody specific for amino acids 256-270 of the DBD (Vojtesek et al. 1995). Different p53 isoforms were expressed in p53-deficient cells in culture, and lysates from these cells were screened for p53 proteins by Western analysis. The anti-p53 sheep polyclonal serum recognized p53, p53 $\beta, \mathrm{p} 53 \gamma, \Delta 40 \mathrm{p} 53, \Delta 133 \mathrm{p} 53$, as well a mutant version of $\Delta 133 \mathrm{p} 53$; however, it did not detect either $\Delta 133 \mathrm{p} 53 \beta$ or $\Delta 133 \mathrm{p} 53 \gamma$, since these isoforms are lacking both the $\mathrm{N}$ and $\mathrm{C}$ termini to which this antibody had been raised. In contrast, DO-12 recognized all six of these p53 isoforms because the DBD is common to each. To determine whether p53 isoforms are detectable in human tumor cell lines, a panel of established lines was analyzed by Western analysis using the DO-12 antibody. While the p53-deficient cell lines H1299 and Saos did not express significant levels of p53, the cell lines SW620, 293, and HT29 expressed multiple p53 proteins robustly.

The p53 antibodies that were currently available were not specific for individual p53 proteins because they had been generated against epitopes common to all p53 isoforms. To generate reagents that could discriminate among the different isoforms of p53, Bourdon et al. (2005) generated a polyclonal antibody (KJC8) against the peptide sequence DQTSFQKENC that is unique to $\mathrm{p} 53 \beta$, $\Delta 40 \mathrm{p} 53 \beta$, and $\Delta 133 \mathrm{p} 53 \beta$ (Fig. $2 \mathrm{~A}$ ). To demonstrate that this antibody is specific for the $\beta$ isoforms, $\mathrm{p} 53$-deficient cells were transfected with $\mathrm{p} 53, \mathrm{p} 53 \beta$, or $\Delta 133 \mathrm{p} 53 \beta$, and lysates were analyzed by Western analysis. When the CM1 antibody that had been generated against fulllength p53 was used, both p53 and p53 $\beta$ were detected, but $\Delta 133 \mathrm{p} 53 \beta$ was not. In contrast, KJC 8 failed to recognize p53, but specifically detected both $\mathrm{p} 53 \beta$ and $\Delta 133$ p $53 \beta$. When siRNA was used to knock down p53 levels in these cells, the CM1 antibody recognized p53 isoforms that were reduced in cells treated with siRNA constructs specific for p53. A similar analysis using the KJC8 antibody determined that siRNA constructs against p53 efficiently reduced levels of both p53 $\beta$ and $\Delta 133 \mathrm{p} 53 \beta$. This analysis demonstrated that the KJC8 antibody is specific for the $\beta$ isoform subclass. While antibodies specific for the unique epitope at the $\mathrm{C}$ terminus of $\mathrm{p} 53 \gamma$ and $\Delta 133 \mathrm{p} 53 \gamma$ were not able to be generated to date, these reagents will be important for further assessing p53 isoforms expression in normal and neoplastic tissues.

\section{Response to DNA damage}

p53 protein is stabilized in response to multiple stimuli including oncogenes, hypoxia, and DNA damage. To determine whether $\mathrm{p} 53 \beta$ and $\Delta 133 \mathrm{p} 53 \beta$ could be induced in a manner similar to p53, MCF-7 mammary epithelial cells (which express endogenous p53) were treated with the chemotherapeutic drug actinomycin D, and lysates were subjected to Western analysis. When the DO-1 antibody that recognizes the $\mathrm{N}$ terminus of p53 was used, p53 protein levels were significantly enhanced in re- 
Mills

sponse to actinomycin $\mathrm{D}$ treatment. In contrast, the KJC8 antibody detected similar levels of p53 $\beta$ and $\Delta 133$ p $53 \beta$ protein in both untreated and actinomycin Dtreated cells. This analysis demonstrates that unlike $\mathrm{p} 53, \mathrm{p} 53 \beta$ and $\Delta 133 \mathrm{p} 53 \beta$ do not appear to be stabilized in response to DNA damage. As previous studies demonstrate that expression of the p53as isoform increases in response to actinomycin $\mathrm{D}$ treatment in normal cells (Kulesz-Martin et al. 1994), further work will be required to determine how DNA-damaging agents selectively trigger the expression of specific p53 isoforms.

\section{Subcellular localization}

To examine the subcellular localization of the various p53 isoforms, H1299 cells were transfected with different p53 isoform-encoding constructs, and immunofluorescence was used to identify the subcellular distribution of p53 proteins. The CM1 antibody detected a nuclear expression pattern for both p53 and $\Delta 133 \mathrm{p} 53$, and a nuclear plus a slight cytoplasmic expression pattern for $\mathrm{p} 53 \beta$ and $\mathrm{p} 53 \gamma$. The KJC8 antibody was used to determine that $\Delta 133 \mathrm{p} 53 \beta$ is expressed in both the nucleus and the cytoplasm. The DO-12 antibody revealed that the $\Delta 133 \mathrm{p} 53 \gamma$ isoform is expressed in the cytoplasm, suggesting that the second alternative exon within intron 9 can modulate subcellular distribution even though the nuclear localization sequence is still present. p53as, with a distinct C-terminal tail, is expressed in the nucleus (Kulesz-Martin et al. 1994). Although cytoplasmic localization has been shown for the p53 isoform $\Delta 40$ p53 (Ghosh et al. 2004), this protein has an N-terminal truncation, whereas the cytoplasmic $\Delta 133 \mathrm{p} 53 \gamma$ has both $\mathrm{N}$ - and C-terminal truncations /see Fig. 2). Deletion of the MDM2-interacting TA1 region in $\Delta 40$ p53 results in monoubiquitination and cytoplasmic localization, as well as a reduction in MDM2-mediated nuclear export and subsequent degradation of full-length p53 (Ghosh et al. 2004). Since $\Delta 133$ p53 lacks the entire TA region, it is unlikely to function similarly to $\Delta 40 \mathrm{p} 53$, which retains the second transactivation domain.

\section{Interaction with full-length p53}

To investigate whether the $\beta$ isoforms can interact with endogenous full-length p53, the KJC8 antibody was used for immunoprecipitation, and Western analysis with the DO-1 antibody specific for the $\mathrm{N}$ terminus of p53 was used to detect p53 isoforms. The KJC8 antibody can efficiently immunoprecipitate p $53 \beta$ while simultaneously pulling down endogenous p53 from MCF-7 cells, indicating that $\mathrm{p} 53 \beta$ can interact with endogenous $\mathrm{p} 53$ in this cell type. It could not be concluded whether this antibody also immunoprecipitates $\Delta 133 \mathrm{p} 53 \beta$ and $\Delta 40 \mathrm{p} 53 \beta$ since DO-1 was used to detect coimmunoprecipitated p53, and this antibody is specific for the transactivation domain and therefore does not detect the $\beta$ isoforms that have an N-terminal truncation (see Fig. 2A). Since p53 $\beta$, $\Delta 40 \mathrm{p} 53 \beta$, and $\Delta 133 \mathrm{p} 53 \beta$ share the epitope to which the
KJC8 antibody was raised, and this antibody was shown to recognize at least two of the $\beta$ isoforms, it is likely that $\mathrm{p} 53 \beta, \Delta 40 \mathrm{p} 53 \beta$, and $\Delta 133 \mathrm{p} 53 \beta$ are immunoprecipitated in this assay, if these isoforms are expressed in MCF-7 cells. Although the authors do not discuss the possibility that $\mathrm{N}$-terminally truncated $\beta$ isoforms may also be pulled down in this assay, it is possible that $\Delta 40 \mathrm{p} 53 \beta$ and $\Delta 133 \mathrm{p} 53 \beta$ also interact with full-length $\mathrm{p} 53$.

\section{Downstream targets}

To examine whether $\mathrm{p} 53 \beta$ (and $\Delta 40 \mathrm{p} 53 \beta$ and $\Delta 133 \mathrm{p} 53 \beta$ ?) can occupy the BAX, p21, and MDM2 promoters, chromatin immunopreciptipation (ChIP) was used. As a positive control, ChIP was performed using the 421 antibody that had been raised against an epitope between amino acids 372 and 382 within exon 11, which does not detect p53 $\beta$ or p53 $\gamma$ because these isoforms are missing this region of the $\mathrm{C}$ terminus. The 421 antibody immunoprecipitated approximately fivefold more p21 and MDM2 promoter relative to the BAX promoter, indicating that p53 binds preferentially to the p21 and MDM2 promoters. The anti-p53 $\beta,-\Delta 40$ p53 $\beta,-\Delta 133$ p $53 \beta$ KJC8 antibody, in contrast, immunoprecipitated approximately sixfold more p21 and BAX promoter relative to the MDM2 promoter, indicating that $\beta$ isoforms preferentially bind $\mathrm{p} 21$ and BAX promoters. Although it is not certain whether $\mathrm{p} 53 \beta, \Delta 40 \mathrm{p} 53 \beta, \Delta 133 \mathrm{p} 53 \beta$, or a combination of $\beta$ isoforms are binding chromatin in this assay (see above), these results demonstrate that at least one of the $\beta$ isoforms can bind the promoters of, and presumably modulate the expression of, a subset of p53-responsive genes.

Since these assays were performed in MCF-7 cells (which express endogenous p53) and p53 $\beta$ can interact with p53, full-length p53 could be mediating the binding of $\mathrm{p} 53 \beta$ to chromatin. In agreement with this possibility, the authors demonstrate that $\mathrm{p} 53 \beta$ is unable to transactivate p21 or BAX reporters in p53-deficient cells. Consistent with p53's ability to occupy the endogenous BAX and p21 promoters in ChIP experiments, p53 can transactivate both the BAX and p21 reporters, although p53's effect in both of these assays is lower for the BAX promoter than it is for the $\mathrm{p} 21$ promoter. When $\mathrm{p} 53 \beta$ and p53 are cotransfected, however, the BAX reporter is transactivated more efficiently than it is by p53 alone, and this effect is significantly enhanced by actinomycin $\mathrm{D}$ treatment. Although $\mathrm{p} 53$ and $\mathrm{p} 53 \beta$ have a synergistic effect on transcriptional activation of the BAX promoter, the $\mathrm{p} 21$ promoter is not further transactivated when $\mathrm{p} 53$ and $\mathrm{p} 53 \beta$ are simultaneously expressed, even though p53 $\beta$ was shown to occupy this promoter in ChIP experiments. The authors demonstrate that $\mathrm{p} 53$ protein levels are not altered by $\mathrm{p} 53 \beta$ expression, and thus conclude that $\mathrm{p} 53 \beta$ can selectively modulate certain p53-responsive genes at the transcript level.

To examine how $\mathrm{p} 53 \beta$ and $\Delta 133 \mathrm{p} 53 \beta$ affect the biological function of a well characterized p53-mediated response-apoptosis, Bourdon et al. (2005) used FACS analysis to detect the sub-G1 population in H1299 cells 
expressing $\mathrm{p} 53 \beta$ or $\Delta 133 \mathrm{p} 53 \beta$. Full-length p53 efficiently induces apoptosis, whereas $\mathrm{p} 53 \beta$ has reduced proapoptotic activity. In contrast, $\Delta 133 \mathrm{p} 53 \beta$ is defective in inducing apoptosis, and can inhibit the pro-apoptotic capabilities of full-length p53. This dominant negative effect of $\mathrm{N}$-terminally truncated isoforms on the activity of full-length isoforms has been demonstrated for both p63 and p73 (Yang et al. 1998; Pozniak et al. 2000; Stiewe et al. 2002; Zaika et al. 2002), underscoring that structural homology between members of the $p 53$ gene family can be extended to mechanistic similarities as well.

Although the molecular mechanism whereby $\Delta 133 \mathrm{p} 53 \beta$ inhibits transactivation of specific p53-modulated target genes, and how specificity between different promoters is achieved, warrant future investigation, the functional features of p53 isoforms described by Bourdon et al. (2005) are quite different from those of earlier reports of p53 isoforms. p53i9, which is identical to p53 $\beta$, was previously reported to be deficient in DNA binding and to have a transcriptional defect (Flaman et al. 1996), whereas the Lane group (Bourdon et al. 2005) demonstrates that not only can $\beta$ isoforms bind chromatin in p53-expressing cells, but that $\mathrm{p} 53 \beta$ isoforms can transcriptionally modulate certain p53-responsive promoters when p53 is present. Although the reason for disparate conclusions between these two studies is not clear, it is likely that the distinct assays used are responsible for these differences. Indeed, the generation of an antibody specific for the $\beta$ isoforms has enhanced the ways in which the function of these p53 isoforms can be explored. In contrast, p53as was shown to be constitutively active for DNA binding (Wu et al. 1994). Although $\Delta 40$ p53 binds DNA, it itself is impaired in transactivation capabilities, and it can even suppress p53-mediated transcription, thereby dampening p53's growth suppressive function (Courtois et al. 2002; Yin et al. 2002; Ghosh et al. 2004). In contrast to the $\beta$ isoforms of $\mathrm{p} 53$, $\Delta$ p53 does not interact with full-length p53 (Rohaly et al. 2005). Although $\Delta$ p53 has a substantial deletion that encompasses the highly conserved region $\mathrm{V}$ of the core DBD while retaining the reading frame, it is still able to transactivate a specific subset of p53-responsive genes involved in cell cycle arrest, but not those involved in apoptosis. The altered transcriptional ability of $\Delta$ p53 mediates an ATR-intra S-phase checkpoint that allows for DNA repair without triggering an apoptotic response (Rohaly et al. 2005). Thus, the different p53 isoforms likely have diverse physiological roles.

\section{Closing remarks}

This work provides further support for the hypothesis that p53-related genes arose by triplication of a more ancestral family member such as the most highly conserved member, $p 63$. If $p 53$ resulted from triplication of a more primordial p53-like gene, does the $p 53$ gene in flies really represent this most ancestral gene? That is, is Drosophila p53 really more closely related to p63 than it is to mammalian $p 53$ ? The work of Bourdon et al. (2005) provides a new look at similarities between $p 53$ family members that makes gene nomenclature based on structure alone less clear. In addition to its insight into evolution of the p53 family of genes, this study has further implications for the role of p53-related genes in both cancer and aging; thus it is probable that the p53 family greatly impacts our future health and longevity. Indeed, Bourdon et al. (2005) found that tumors that retain wildtype $p 53$ often express an abnormal balance of p53 isoforms. Since N-terminally truncated p53 isoforms can regulate p53 activity, an alteration in the ratio of different p53 isoforms may predispose to cancer, and might even explain the lack of correlation between p53 mutational status and response to anti-cancer therapies. In addition, it is likely that an imbalance in p53 isoform expression could accelerate the aging process. Indeed, the presence of endogenously expressed $\mathrm{N}$-terminally truncated p53 isoforms likely explains the fact that although three different mouse models with enhanced p53 activity have been generated (Garcia-Cao et al. 2002; Tyner et al. 2002; Maier et al. 2004) and these mice are not susceptible to spontaneous tumors (Garcia-Cao et al. 2002; Tyner et al. 2002), only two of these models develop concomitant accelerated aging phenotypes (Tyner et al. 2002; Maier et al. 2004). The model that ages normally was generated by overexpression of the entire $p 53$ locus, presumably causing increased expression of all p53 isoforms, whereas the models that display accelerated aging phenotypes express enhanced levels of p53 isoforms with $\mathrm{N}$-terminal truncations, suggesting that a balance between p53 isoforms is essential for tissue homeostasis and longevity. Lastly, this work will likely shed light on the intricate network involving members of the p53 family. Indeed, recent work from my laboratory demonstrates that p63 deficiency induces cellular senescence and leads to an accelerated aging phenotype in vivo, suggesting that longevity is regulated by interactions between p53 and p63 (Keyes et al. 2005). In addition, although spontaneous tumors have been reported in one particular p63-deficient mouse model, a distinct p63-deficient mouse model is not prone to $\gamma$-irradiationinduced (Perez-Losada et al. 2005), spontaneous, or chemically induced tumors (W.M. Keyes and A. Mills, unpubl.), whereas mice overexpressing TAp63 $\alpha$ are predisposed to skin cancer in response to carcinogens (M.I. Koster, S.-L. Lu, X.-J. Wang, and D.R. Roop, in prep). Intriguingly, the p63 heterozygous mouse model in which tumors were observed harbors an allele that deletes exons encoding a portion of the DBD (Yang et al. 1999; Flores et al. 2005). This deletion maintains the reading frame, a situation that could generate a p63 isoform that is functionally similar to $\Delta$ p53 (Rohaly et al. 2005). Future experiments will be needed to gain further insight into how the array of p53 isoforms described by the Lane group (Bourdon et al. 2005) modulate the function(s) of p53-related proteins p63 and p73. This will provide a better understanding of how the $p 53$ family of genes evolved, and will undoubtedly impact the fields of both cancer and aging. Thus, as Alex Haley wrote, "in every conceivable manner, the [p53] family is link to our past, bridge to our future." 


\section{Acknowledgments}

I thank Bill Tansey for helpful discussions, and Cristian Papazoglu for critical reading of the manuscript.

\section{References}

Arai, N., Nomura, D., Yokota, K., Wolf, D., Brill, E., Shohat, O., and Rotter, V. 1986. Immunologically distinct p53 molecules generated by alternative splicing. Mol. Cell. Biol. 6: 3232-3239.

Bienz-Tadmor, B., Zakut-Houri, R., Libresco, S., Givol, D., and Oren, M. 1985. The $5^{\prime}$ region of the p53 gene: Evolutionary conservation and evidence for a negative regulatory element. EMBO I. 4: 3209-3213.

Bourdon, J.C., Fernandes, K., Murray-Zmijewski, F., Liu, G., Diot, A., Xirodimas, D.P., Saville, M.K., and Lane, D.P. 2005. p53 isoforms can regulate p53 transcriptional acivity. Genes \& Dev. (this issue).

Brodsky, M.H., Nordstrom, W., Tsang, G., Kwan, E., Rubin, G.M., and Abrams, J.M. 2000. Drosophila p53 binds a damage response element at the reaper locus. Cell 101: 103-113.

Choi, H.R., Batsakis, J.G., Zhan, F., Sturgis, E., Luna, M.A., and El-Naggar, A.K. 2002. Differential expression of p53 gene family members p63 and p73 in head and neck squamous tumorigenesis. Hum. Pathol. 33: 158-164.

Chow, V.T., Quek, H.H., and Tock, E.P. 1993. Alternative splicing of the p53 tumor suppressor gene in the Molt-4 T-lymphoblastic leukemia cell line. Cancer Lett. 73: 141-148.

Courtois, S., Verhaegh, G., North, S., Luciani, M.G., Lassus, P., Hibner, U., Oren, M., and Hainaut, P. 2002. $\Delta$ N-p53, a natural isoform of p53 lacking the first transactivation domain, counteracts growth suppression by wild-type p53. Oncogene 21: 6722-6728.

Crook, T., Nicholls, J.M., Brooks, L., O'Nions, J., and Allday, M.J. 2000. High level expression of $\Delta \mathrm{N}-\mathrm{p} 63$ : A mechanism for the inactivation of p53 in undifferentiated nasopharyngeal carcinoma (NPC)? Oncogene 19: 3439-3444.

Di Como, C.J., Urist, M.J., Babayan, I., Drobnjak, M., Hedvat, C.V., Teruya-Feldstein, J., Pohar, K., Hoos, A., and CordonCardo, C. 2002. p63 expression profiles in human normal and tumor tissues. Clin. Cancer Res. 8: 494-501.

Flaman, J.M., Waridel, F., Estreicher, A., Vannier, A., Limacher, J.M., Gilbert, D., Iggo, R., and Frebourg, T. 1996. The human tumour suppressor gene p53 is alternatively spliced in normal cells. Oncogene 12: 813-818.

Flores, E.R., Sengupta, S., Miller, J.B., Newman, J.J., Bronson, R., Crowley, D., Yang, A., McKeon, F., and Jacks, T. 2005. Tumor predisposition in mice mutant for p63 and p73: Evidence for broader tumor suppressor functions for the p53 family. Cancer Cell 7: 363-373.

Gaiddon, C., Lokshin, M., Ahn, J., Zhang, T., and Prives, C. 2001. A subset of tumor-derived mutant forms of p53 downregulate $\mathrm{p} 63$ and $\mathrm{p} 73$ through a direct interaction with the p53 core domain. Mol. Cell. Biol. 21: 1874-1887.

Garcia-Cao, I., Garcia-Cao, M., Martin-Caballero, J., Criado, L.M., Klatt, P., Flores, J.M., Weill, J.C., Blasco, M.A., and Serrano, M. 2002. 'Super p53' mice exhibit enhanced DNA damage response, are tumor resistant and age normally. EMBO J. 21: 6225-6235.

Ghosh, A., Stewart, D., and Matlashewski, G. 2004. Regulation of human p53 activity and cell localization by alternative splicing. Mol. Cell. Biol. 24: 7987-7997.

Han, K.A. and Kulesz-Martin, M.F. 1992. Alternatively spliced p53 RNA in transformed and normal cells of different tissue types. Nucleic Acids Res. 20: 1979-1981.
Hibi, K., Trink, B., Patturajan, M., Westra, W.H., Caballero, O.L., Hill, D.E., Ratovitski, E.A., Jen, J., and Sidransky, D. 2000. AIS is an oncogene amplified in squamous cell carcinoma. Proc. Natl. Acad. Sci. 97: 5462-5467.

Hu, H., Xia, S.H., Li, A.D., Xu, X., Cai, Y., Han, Y.L., Wei, F., Chen, B.S., Huang, X.P., Han, Y.S., et al. 2002. Elevated expression of p63 protein in human esophageal squamous cell carcinomas. Int. J. Cancer 102: 580-583.

Ito, Y., Takeda, T., Wakasa, K., Tsujimoto, M., Sakon, M., and Matsuura, N. 2001. Expression of p73 and p63 proteins in pancreatic adenocarcinoma: p73 overexpression is inversely correlated with biological aggressiveness. Int. I. Mol. Med. 8: $67-71$.

Jin, S., Martinek, S., Joo, W.S., Wortman, J.R., Mirkovic, N., Sali, A., Yandell, M.D., Pavletich, N.P., Young, M.W., and Levine, A.J. 2000. Identification and characterization of a p53 homologue in Drosophila melanogaster. Proc. Natl. Acad. Sci. 97: 7301-7306.

Kaghad, M., Bonnet, H., Yang, A., Creancier, L., Biscan, J.C., Valent, A., Minty, A., Chalon, P., Lelias, J.M., Dumont, X., et al. 1997. Monoallelically expressed gene related to p53 at $1 \mathrm{p} 36$, a region frequently deleted in neuroblastoma and other human cancers. Cell 90: 809-819.

Keyes, W.M., Wu, Y., Vogel, H., Guo, X., Lowe, S.W., and Mills, A.A. p63 deficiency activates a program of cellular senescence and leads to accelerated aging. Genes \& Dev. 19: 1986-1999.

Kulesz-Martin, M.F., Lisafeld, B., Huang, H., Kisiel, N.D., and Lee, L. 1994. Endogenous p53 protein generated from wildtype alternatively spliced p53 RNA in mouse epidermal cells. Mol. Cell. Biol. 14: 1698-1708.

Lamb, P. and Crawford, L. 1986. Characterization of the human p53 gene. Mol. Cell. Biol. 6: 1379-1385.

Lane, D.P. and Crawford, L.V. 1979. T antigen is bound to a host protein in SV40-transformed cells. Nature 278: 261-263.

Laverdiere, M., Beaudoin, J., and Lavigueur, A. 2000. Speciesspecific regulation of alternative splicing in the C-terminal region of the p53 tumor suppressor gene. Nucleic Acids Res. 28: 1489-1497.

Maier, B., Gluba, W., Bernier, B., Turner, T., Mohammad, K., Guise, T., Sutherland, A., Thorner, M., and Scrable, H. 2004. Modulation of mammalian life span by the short isoform of p53. Genes \& Dev. 18: 306-319.

Massion, P.P., Taflan, P.M., Jamshedur Rahman, S.M., Yildiz, P., Shyr, Y., Edgerton, M.E., Westfall, M.D., Roberts, J.R., Pietenpol, J.A., Carbone, D.P., et al. 2003. Significance of p63 amplification and overexpression in lung cancer development and prognosis. Cancer Res. 63: 7113-7121.

Matlashewski, G., Banks, L., Pim, D., and Crawford, L. 1986. Analysis of human p53 proteins and mRNA levels in normal and transformed cells. Eur. J. Biochem. 154: 665-672.

Midgley, C.A., Fisher, C.J., Bartek, J., Vojtesek, B., Lane, D., and Barnes, D.M. 1992. Analysis of p53 expression in human tumours: An antibody raised against human p53 expressed in Escherichia coli. J. Cell Sci. 101 (Pt 1): 183-189.

Miki, Y., Swensen, J., Shattuck-Eidens, D., Futreal, P.A., Harshman, K., Tavtigian, S., Liu, Q., Cochran, C., Bennett, L.M., Ding, W., et al. 1994. A strong candidate for the breast and ovarian cancer susceptibility gene BRCA1. Science 266: 66-71.

Milner, J., Medcalf, E.A., and Cook, A.C. 1991. Tumor suppressor p53: Analysis of wild-type and mutant p53 complexes. Mol. Cell. Biol. 11: 12-19.

Mullis, K.B. and Faloona, F.A. 1987. Specific synthesis of DNA in vitro via a polymerase-catalyzed chain reaction. Methods Enzymol. 155: 335-350.

Mullis, K., Faloona, F., Scharf, S., Saiki, R., Horn, G., and Erlich, 
H. 1986. Specific enzymatic amplification of DNA in vitro: The polymerase chain reaction. Cold Spring Harb. Symp. Quant. Biol. 51 Pt 1: 263-273.

Ollmann, M., Young, L.M., Di Como, C.J., Karim, F., Belvin, M., Robertson, S., Whittaker, K., Demsky, M., Fisher, W.W., Buchman, A., et al. 2000. Drosophila p53 is a structural and functional homolog of the tumor suppressor p53. Cell 101: 91-101.

Patturajan, M., Nomoto, S., Sommer, M., Fomenkov, A., Hibi, K., Zangen, R., Poliak, N., Califano, J., Trink, B., Ratovitski, E., et al. 2002. $\Delta$ Np63 induces $\beta$-catenin nuclear accumulation and signaling. Cancer Cell 1: 369-379.

Perez-Losada, J., Wu, D., Delrosario, R., Balmain, A., and Mao, J.H. 2005. p63 and p73 do not contribute to p53-mediated lymphoma suppressor activity in vivo. Oncogene (in press). [Epub June 20.]

Pozniak, C.D., Radinovic, S., Yang, A., McKeon, F., Kaplan, D.R., and Miller, F.D. 2000. An anti-apoptotic role for the p53 family member, p73, during developmental neuron death [see comments]. Science 289: 304-306.

Pruneri, G., Fabris, S., Dell'Orto, P., Biasi, M.O., Valentini, S., Del Curto, B., Laszlo, D., Cattaneo, L., Fasani, R., Rossini, L., et al. 2005. The transactivating isoforms of p63 are overexpressed in high-grade follicular lymphomas independent of the occurrence of p63 gene amplification. J. Pathol. 206: 337-345.

Quade, B.J., Yang, A., Wang, Y., Sun, D., Park, J., Sheets, E.E., Cviko, A., Federschneider, J.M., Peters, R., McKeon, F.D., et al. 2001. Expression of the p53 homologue p63 in early cervical neoplasia. Gynecol. Oncol. 80: 24-29.

Reis-Filho, J.S., Torio, B., Albergaria, A., and Schmitt, F.C. 2002. p63 expression in normal skin and usual cutaneous carcinomas. J. Cutan. Pathol. 29: 517-523.

Reis-Filho, J.S., Simpson, P.T., Martins, A., Preto, A., Gartner, F., and Schmitt, F.C. 2003. Distribution of p63, cytokeratins $5 / 6$ and cytokeratin 14 in 51 normal and 400 neoplastic human tissue samples using TARP-4 multi-tumor tissue microarray. Virchows Arch. 443: 122-132.

Reisman, D., Greenberg, M., and Rotter, V. 1988. Human p53 oncogene contains one promoter upstream of exon 1 and a second, stronger promoter within intron 1. Proc. Natl. Acad. Sci. 85: 5146-5150.

Reisman, D., Balint, E., Loging, W.T., Rotter, V., and Almon, E. 1996. A novel transcript encoded within the $10-\mathrm{kb}$ first intron of the human p53 tumor suppressor gene (D17S2179E) is induced during differentiation of myeloid leukemia cells. Genomics 38: 364-370.

Rohaly, G., Chemnitz, J., Dehde, S., Nunez, A.M., Heukeshoven, J., Deppert, W., and Dornreiter, I. 2005. A novel human p53 isoform is an essential element of the ATRintra-S phase checkpoint. Cell 122: 21-32.

Rovinski, B., Munroe, D., Peacock, J., Mowat, M., Bernstein, A., and Benchimol, S. 1987. Deletion of $5^{\prime}$-coding sequences of the cellular p53 gene in mouse erythroleukemia: A novel mechanism of oncogene regulation. Mol. Cell. Biol. 7: 847-853.

Schmale, H. and Bamberger, C. 1997. A novel protein with strong homology to the tumor suppressor p53. Oncogene 15: $1363-1367$.

Stephen, C.W., Helminen, P., and Lane, D.P. 1995. Characterisation of epitopes on human p53 using phage-displayed peptide libraries: Insights into antibody-peptide interactions. $J$. Mol. Biol. 248: 58-78.

Stiewe, T., Theseling, C.C., and Putzer, B.M. 2002. Transactivation-deficient $\Delta$ TA-p 73 inhibits $\mathrm{p} 53$ by direct competition for DNA binding: Implications for tumorigenesis. J. Biol. Chem. 277: 14177-14185.
Strano, S., Munarriz, E., Rossi, M., Cristofanelli, B., Shaul, Y., Castagnoli, L., Levine, A.J., Sacchi, A., Cesareni, G., Oren, M., et al. 2000. Physical and functional interaction between p53 mutants and different isoforms of p73. J. Biol. Chem. 275: 29503-29512.

Strano, S., Fontemaggi, G., Costanzo, A., Rizzo, M.G., Monti, O., Baccarini, A., Del Sal, G., Levrero, M., Sacchi, A., Oren, M., et al. 2002. Physical interaction with human tumor-derived p53 mutants inhibits p63 activities. J. Biol. Chem. 277: $18817-18826$.

Tonon, G., Wong, K.K., Maulik, G., Brennan, C., Feng, B., Zhang, Y., Khatry, D.B., Protopopov, A., You, M.J., Aguirre, A.J., et al. 2005. High-resolution genomic profiles of human lung cancer. Proc. Natl. Acad. Sci. 102: 9625-9630.

Tyner, S.D., Venkatachalam, S., Choi, J., Jones, S., Ghebranious, N., Igelmann, H., Lu, X., Soron, G., Cooper, B., Brayton, C., et al. 2002. p53 mutant mice that display early ageing-associated phenotypes. Nature 415: 45-53.

Vojtesek, B., Dolezalova, H., Lauerova, L., Svitakova, M., Havlis, P., Kovarik, J., Midgley, C.A., and Lane, D.P. 1995. Conformational changes in p53 analysed using new antibodies to the core DNA binding domain of the protein. Oncogene 10: 389-393.

Wang, T.Y., Chen, B.F., Yang, Y.C., Chen, H., Wang, Y., Cviko, A., Quade, B.J., Sun, D., Yang, A., McKeon, F.D., et al. 2001. Histologic and immunophenotypic classification of cervical carcinomas by expression of the p53 homologue p63: A study of 250 cases. Hum. Pathol. 32: 479-486.

Wang, B.Y., Gil, J., Kaufman, D., Gan, L., Kohtz, D.S., and Burstein, D.E. 2002. P63 in pulmonary epithelium, pulmonary squamous neoplasms, and other pulmonary tumors. Hum. Pathol. 33: 921-926.

Will, K., Warnecke, G., Bergmann, S., and Deppert, W. 1995. Species- and tissue-specific expression of the C-terminal alternatively spliced form of the tumor suppressor p53. Nucleic Acids Res. 23: 4023-4028.

Wolf, D., Harris, N., Goldfinger, N., and Rotter, V. 1985. Isolation of a full-length mouse cDNA clone coding for an immunologically distinct p53 molecule. Mol. Cell. Biol. 5: 127-132.

Wu, Y., Liu, Y., Lee, L., Miner, Z., and Kulesz-Martin, M. 1994. Wild-type alternatively spliced p53: Binding to DNA and interaction with the major p53 protein in vitro and in cells. EMBO J. 13: 4823-4830.

Yamaguchi, K., Wu, L., Caballero, O.L., Hibi, K., Trink, B., Resto, V., Cairns, P., Okami, K., Koch, W.M., Sidransky, D., et al. 2000. Frequent gain of the p40/p51/p63 gene locus in primary head and neck squamous cell carcinoma. Int. J. Cancer 86: 684-689.

Yang, A., Kaghad, M., Wang, Y., Gillett, E., Fleming, M.D., Dotsch, V., Andrews, N.C., Caput, D., and McKeon, F. 1998. p63, a p53 homolog at 3q27-29, encodes multiple products with transactivating, death-inducing, and dominant-negative activities. Mol. Cell 2: 305-316.

Yang, A., Schweitzer, R., Sun, D., Kaghad, M., Walker, N., Bronson, R.T., Tabin, C., Sharpe, A., Caput, D., Crum, C., et al. 1999. p63 is essential for regenerative proliferation in limb, craniofacial and epithelial development. Nature 398: 714-718.

Yin, Y., Stephen, C.W., Luciani, M.G., and Fahraeus, R. 2002. p53 stability and activity is regulated by Mdm2-mediated induction of alternative p53 translation products. Nat. Cell Biol. 4: 462-467.

Zaika, A.I., Slade, N., Erster, S.H., Sansome, C., Joseph, T.W., Pearl, M., Chalas, E., and Moll, U.M. 2002. $\Delta$ Np73, a dominant-negative inhibitor of wild-type p53 and TAp73, is upregulated in human tumors. J. Exp. Med. 196: 765-780. 


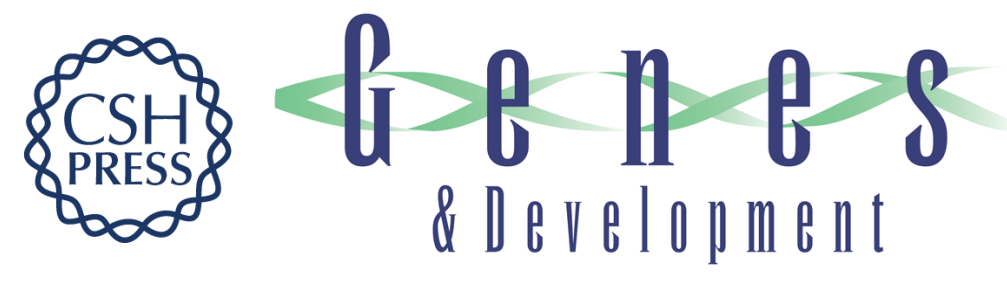

\section{p53: link to the past, bridge to the future}

Alea A. Mills

Genes Dev. 2005, 19:

Access the most recent version at doi:10.1101/gad.1362905

References This article cites 59 articles, 23 of which can be accessed free at: http://genesdev.cshlp.org/content/19/18/2091.full.html\#ref-list-1

License

Email Alerting Receive free email alerts when new articles cite this article - sign up in the box at the top Service right corner of the article or click here.

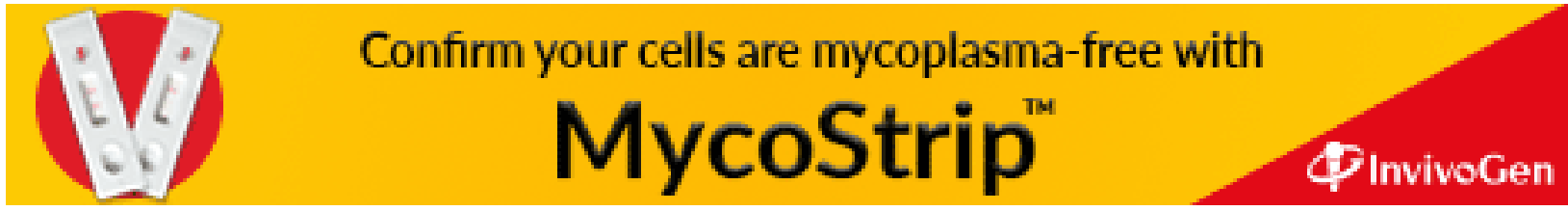

